\title{
Evaluation of Sedative and Hypnotic Activity of Valeriana wallichii Roots on Animal Models
}

Anil Kumar Bonthu, Vasundhara Boosani, Sai Giridhar Reddy Bugulu, Soujanya Burgu, Narender Boggula, Vasudha Bakshi, Rajendra Kumar Jadi, Yaso Deepika Mamidisetti*

School of Pharmacy, Anurag University, Venkatapur, Ghatkesar, Hyderabad, Telangana, India

*Assistant Professor, Department of Pharmacology, School of Pharmacy, Anurag University, Venkatapur, Ghatkesar, Hyderabad, Telangana, India

*Corresponding author: Yaso Deepika Mamidisetti

\section{Abstract}

Background and Aim: Valeriana is a well-known Indian traditional medicinal herb with sleep remedy. Valeriana wallichii (Tagara) is perennial herb of Valerianaceae family growing on higher altitude. Experimental studies proved its activity on anxiety, stress, sleep, depression, performance, alertness, GABA receptor, Hence an effort was made to study the ethnopharmacological uses of $V$. wallichii. Sedative drugs mostly cause dose-dependent depression of the central nervous system which results in hypnosis and anaesthesia possibly; however, these agents are associated with some side effects ranging respiratory, digestive, immune system dysfunctions, tolerance, cognitive function deterioration, and physical dependence; hence, investigations of newer and safer agents are, therefore, imperative. The current study was aimed at investigating the sedative and hypnotic activity of the ethanol root extract of Valeriana wallichii in mice. Methods: The roots of Valeriana wallichii were extracted with ethanol following soxhlation process and tested for the presence of phytochemical constituents. The sedative and hypnotic activity were then investigated using Hole cross, Open field, Hole board and Rota rod tests in mice at the doses of 50, 100, and 200mg/kg of EEVW (ethanolic extract of roots of Valeriana wallichii). Diazepam at the dose of $1 \mathrm{mg} / \mathrm{kg}$ was used as a reference drug in all the experiments. Results: We found that EEVW produced a significant dose dependent inhibition of locomotor activity of mice both in Hole cross and Open field tests $(P<0.05)$. Besides, it also decreased Rota rod performances and the number of head dips in hole-board test. Conclusion: Our study suggests that EEVW may possess sedative principles with potent hypnotic properties. Further investigation is required in the area of pharmacokinetics and toxicology to contribute additional information on the therapeutic use and quality control of the plants.

Keywords: Valeriana wallichii, Hole Board test, sedative and hypnotic activity, Rota Rod test, Hole Cross test. Copyright @ 2020: This is an open-access article distributed under the terms of the Creative Commons Attribution license which permits unrestricted use, distribution, and reproduction in any medium for non-commercial use (NonCommercial, or CC-BY-NC) provided the original author and source are credited.

\section{INTRODUCTION}

In recent years, increasing numbers of people have been choosing herbal medicines or products to improve their health conditions, either alone or in combination with others. Herbs are staging a comeback and herbal "renaissance" occurs all over the world. According to the World Health of Organization (WHO), $75 \%$ of the world's populations are using herbs for basic healthcare needs. Since the dawn of mankind, in fact, the use of herbs/plants has offered an effective medicine for the treatment of illnesses [1,2]. Moreover, many conventional/pharmaceutical drugs are derived directly from both nature and traditional remedies distributed around the world. Up to now, the practice of herbal medicine entails the use of more than 53,000 species, and a number of these are facing the threat of extinction due to overexploitation. Attention focused on the depletion of plant resources on earth in meeting the increasing demand for herbs [3].

Herbalism is a traditional medicinal or folk medicine practice based on the use of plants and plant extracts. Herbs/plants, the major component of Traditional Materia Medica in the world, are of the main forms of life on earth. It is estimated that there are about 350,000 species of existing plants (including seed plants, bryophytes, and ferns), among which 287,655 species have been identified as of 2004 [4, 5]. Herbal Medicine (HM), also called botanical medicine, phytomedicine or phytotherapy, refers to herbs, herbal materials, herbal preparations, and finished herbal products that contain parts of plants or other materials as active ingredients. The plant parts used in herbal therapy include seeds, berries, roots, leaves, fruits, bark, flowers, or even the whole plants. Man was mainly 
dependent on crude botanical material for medical needs to retain vitality and cure diseases prior to the introduction of aspirin derived from Spiraea ulmaria which was already prescribed for fever and swelling in Egyptian papyri and recommended by the Greek Hippocrates for pain and fever [6,7].

Although written records about medicinal plants dated back at least 5,000 years to the Sumerians, who described well-established medicinal uses for such plants as laurel, caraway, and thyme, archeological studies have shown that the practice of herbal medicine dates as far back as 60,000 years ago in Iraq and 8,000 years ago in China. With the advent of western medicine (or "conventional" medicine) over the past century, herbal medicine has been challenged by practitioners of mainstream medicine because of the lack of scientific evidence in the context of contemporary medicine, despite its long history of effective use [8]. Interestingly, things change with time. In recent years, there has been a resurgence of the use of herbs due to the side effects of chemical drugs, lack of curative modern therapies for several chronic diseases, and microbial resistance, as well as the unprecedented investment in pharmaceutical Research and Development (R \& D). For example, only about 1,200 new drugs have been approved by the US Food and Drug Administration (FDA) since 1950. As a result, the use of herbs and herbal products for health purposes has increased in popularity worldwide over the past 40 years, in both the developing and the industrialized countries. Moreover, global pharmaceutical companies armed with modern science/technology and ideas have begun to rediscover herbs as a potential source of new drug candidates and renewed their strategies in favour of natural product drug development and discovery [9$11]$.

Nowadays, many practitioners of "conventional" medicine do not hesitate to recommend herbs, herbal products, or Complementary and Alternative Medicine (CAM) therapy to their patients for the effective treatment of certain diseases. A survey in 2007 indicated that about $40 \%$ of adults and $11 \%$ of children used CAM Therapy (CAMT), and among the adult users, white and black adults constituted $43.1 \%$ and $25.5 \%$, respectively. In addition, CAM and herbal medicines are more commonly used by people with higher levels of education and income. In this context, a 2012 study indicated that the use of CAM significantly correlated with higher education level, with a trend towards greater use in younger patients with breast cancer.Although at present, we do not fully understand the exact facts and mechanisms underlying most traditional remedies and/or how they prevent disease that does not affect the enthusiasm of the public to accept CAM/CAMT. Although there is a wide variety of CAM and CAMT around the world, they can all be divided into two main categories, namely, drug-based CAM/CAMT and non-drug-based CAM/CAMT [12$15]$.

Our earlier endeavours, which focused on discussing the current research and development of Chinese Herbal Medicine (CHM), and the trend in drug discovery, as well as a variety of CAM, aimed to promote the utilization of natural and traditional resources for contemporary health care, including food/diet therapy. As a continuing effort, the current paper will give an overview on herbal medicine from China, India, and Arabia, which are the three most influential traditional medicine systems to improve public health problems $[15,16]$.

Insomnia, the difficulty in initiating or maintaining sleep, was first recorded in Egyptian medical papyri, with use of opium as a hypnotic to relieve insomnia and lavender as herbal sleep remedy in addition to its use for preserving mummies in the belief that death is eternal sleep. The ancient Indian text on Ayurvedic medicine, Charaka Samhita, written around $600 \mathrm{BC}$, describes herbal remedies for insomnia as well as non-pharmacological measures such as massage, warm bath, drinking milk, and listening to music. Although sleep disorders were known in ancient Chinese medicine, systematic description of these including insomnia was recorded in Huangdi Neijing (407-310 BC), with use of herbs and acupuncture for treatment. In Greek medicine, insomnia is reflected in Aristotle writings on sleeplessness in 350 BC. In Arab medicine, Avicenna s Canon of Medicine, which was written in $1632 \mathrm{AD}$, described behavioural as well as pharmacological approaches for the treatment of insomnia $[17,18]$.

The aim of the present research work is to assess the sedative and hypnotic activity of Valeriana wallichii root ethanolic extract using Swiss Albino mice. 


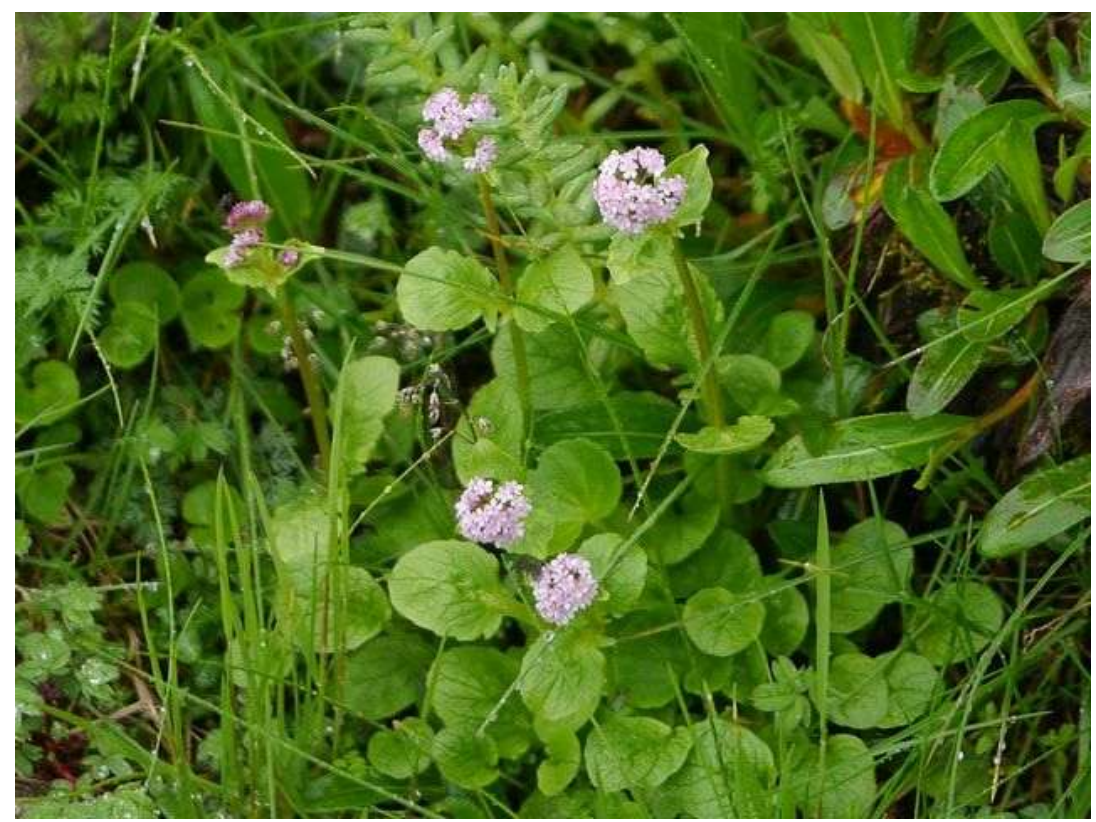

Fig-1: Valeriana wallichii plant

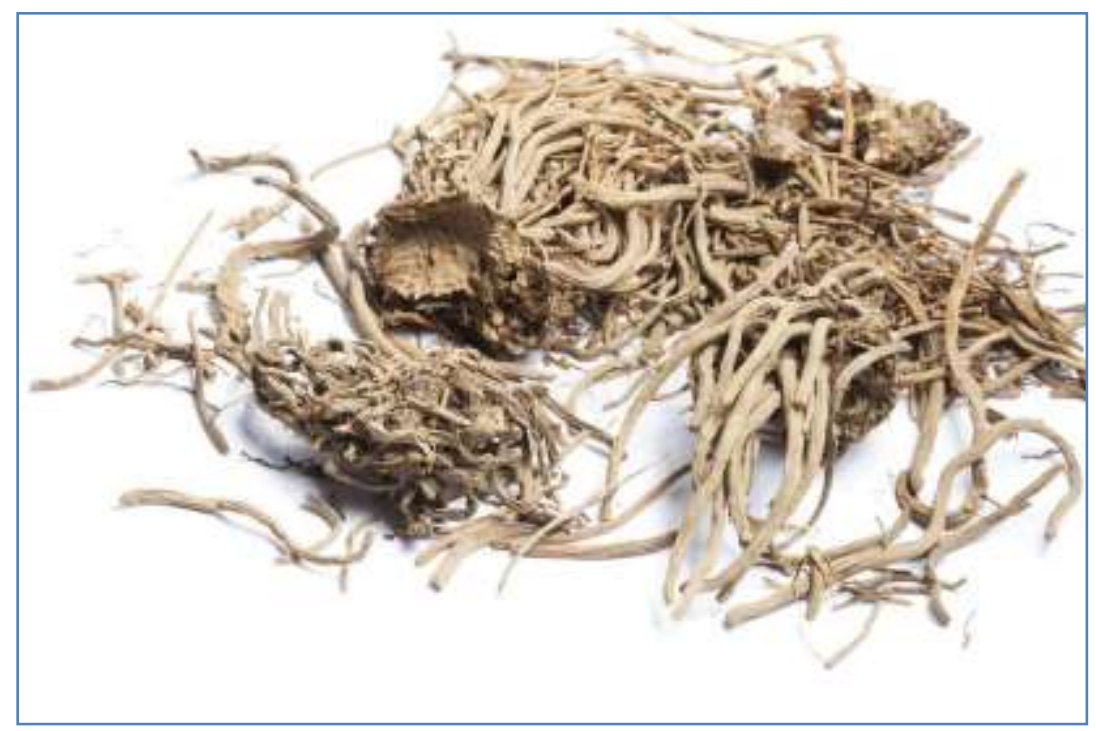

Fig-2: Valeriana wallichii roots

\section{MATERIALS AND METHODS \\ Ethical approval}

This experiment was approved by the Institutional Animal Ethical Committee (I/IAEC/AGI/021/2018 WR ${ }^{+}+\jmath^{\text {) }}$ ), School of Pharmacy, Anurag University, Venkatapur, Ghatkesar, Telangana.

\section{Study area}

The investigation was conducted at Pharmacology Laboratory, Department of Pharmacology, School of Pharmacy, Anurag University, Venkatapur, Ghatkesar, Telangana.

\section{Plant material}

The freshly plant was collected from local market in Hyderabad, Telangana.

\section{Processing and extraction}

Roots of Valeriana wallichii was under the shade air dried for 4 weeks and mechanically pounded into fine particles using electronic grinder. About $500 \mathrm{~g}$ of the pounded plant materials were weighed and extracted by soxhlation for $72 \mathrm{~h}$ in absolute ethanol. The extracts were then filtered, evaporated to dryness, and stored in capped bottles inside the refrigerator at 4 ${ }^{0} \mathrm{C}$ until used.

\section{Experimental animals}

Swiss albino mice of 20-25g were collected from Animal Resources Branch of the Department of Pharmacology. The animals were kept in standard laboratory conditions (relative humidity 55-60\%; room temperature $25 \pm 2{ }^{0} \mathrm{C} ; 12 \mathrm{~h} \mathrm{light/dark}$ cycle) and were provided with standard diet (ICDDR, B formulated) and clean water ad libitum during acclimatization period. 
The animals were acclimatized to the laboratory environment for a period of 14 days prior to performing the experiments. The animals were fasted overnight before the experiments. The experiment protocol was approved by an Institutional Animal Ethical Committee (IAEC) and care of the animals was taken as per guidance of the Committee for the Process of Control and Supervision of Experiments on Animals (CPCSEA).

\section{Drugs and treatments}

The animals were divided into five groups containing 5-7 animals each for control, standard, and test sample for every experiment. EEVW (ethanolic extract of roots of Valeriana wallichii) was dissolved in DMSO (Dimethyl sulfoxide) and orally administered to the test animals $30 \mathrm{~min}$ before the experiments at the doses of 50,100 , and $200 \mathrm{mg} / \mathrm{kg}$ body weight. On the other hand, the standard drug diazepam (1mg/kg) employed in all tests was administered intraperitoneally (i.p.) $15 \mathrm{~min}$ before the experiments where thiopental sodium $(20 \mathrm{mg} / \mathrm{kg})$ in sleeping time measurement test was administered 15 min after treatment with diazepam and $30 \mathrm{~min}$ of vehicle (DMSO) or EEVW. The animals in control group received vehicle orally at the dose of $0.1 \mathrm{~mL} /$ mouse $30 \mathrm{~min}$ before the experiments.

\section{Acute toxicity test}

At the single oral limit dose of $2000 \mathrm{mg} / \mathrm{kg}$, in a group of six mice, no signs of abnormality, morbidity or mortality were observed during 14 days of observation. Chronic toxicity study significant differences between the treated and control groups were observed in the following parameters: Loss of Auditory startle (alarm reaction), Aggressiveness (Control > treated), Nasal discharge, Dyspnoea.

\section{Chronic toxicity}

There were 6 deaths during the study, but there was no significant difference in mortality rate between groups. At necropsy, tracheitis was observed in 3 cases. Histopathological analysis of liver and kidney samples did not show any sign of toxicity in any of the tested animals. Results from Photoactometer test indicates dose dependent increase in sedative property without motor in coordination as indicated by all animals passing rota rod test.

From this work it could be concluded that Valeriana wallichii rhizome hydroethanolic extract didn't exhibit mortality, morbidity or any other neurologic, hematologic or biochemical adverse effects apart from sedation which is extension of their known pharmacological activity, after single oral dose of $2000 \mathrm{mg} / \mathrm{kg}$ bw (14 days of observation) or after once daily $200 \mathrm{mg} / \mathrm{kg}, 600 \mathrm{mg} / \mathrm{kg} 1800 \mathrm{mg} / \mathrm{kg}$ oral treatment for 90 days in healthy adult Swiss albino mice.

\section{Hole Cross Test}

For this experiment, a cage was used having a size of $30 \times 20 \times 14 \mathrm{~cm}$ with a fixed partition in the middle having a hole of $3 \mathrm{~cm}$ diameter [19]. The animals were treated with either vehicle or drug or EEVW and allowed to cross the hole from one chamber to another. Mice were observer for $3 \mathrm{~min}$ and the number of passages was recorded at $30,60,90$, and 120 min following the treatments.

\section{Open Field Test}

This method was carried out as described by Gupta et al. [20]. The open field apparatus consisted of a wooden field of half square meter with a series of squares alternatively painted in black and white. It had a wall of $50 \mathrm{~cm}$ height and was placed in a dimly lit room. Mice were treated with vehicle, extract, or diazepam and were placed in the middle of the open field. Then the number of squares visited by the animals was counted for $3 \mathrm{~min}$ at $30,60,90$, and $120 \mathrm{~min}$ after the treatments.

\section{Hole Board Test}

The hole-board test was performed according to the previously described method by Ozturk et al. [21], with slight modifications. For this test, we used a flat platform of $60 \mathrm{~cm} \times 30 \mathrm{~cm}$ in diameter with 16 evenly spaced holes. In brief, thirty minutes after vehicle or EEVW and $15 \mathrm{~min}$ after diazepam administration, each animal was allowed to move on the platform and the number of head dips into the holes was counted for $5 \mathrm{~min}$.

\section{Test for Motor Coordination (Rota Rod Test) in Mice}

This test was performed using a horizontal rotation rod (Ugo Basile, Varese, Italy) set at a rate of 20 revolutions per min. Mice that were able to remain on the rod longer than $180 \mathrm{~s}$ were selected and divided into desired groups. Thirty minutes after the vehicle or EEVW administration, each mouse was placed on the rod for $180 \mathrm{~s}$ where diazepam was given $15 \mathrm{~min}$ before the experiment [22]. Then the falling time from the rotating rod was recorded for each mouse.

\section{STATISTICAL ANALYSIS}

The results are presented as Mean \pm SEM. The statistical analysis was performed using one-way analysis of variance (ANOVA) followed by Dunnett's post hoc test, except for the hole cross test and open field test. For these tests, two-way ANOVA followed by Bonferroni post hoc tests was adopted. All statistical analysis was performed using SPSS 11.5 software.

\section{RESULTS AND DISCUSSION}

Various herbal medicines are used in the treatment of anxiety and insomnia. Despite their increasing use and the growing interest in such medicines, evidence of effectiveness is still lacking. Specifically, their use in patients with bipolar disorder 
has seldom been studied. Of all herbal medicines discussed in this paper, kava, valerian, and SJW have been studied the most extensively. Based on currently available evidence, valerian seems to be the most promising agent. Lemon balm is also thought to be beneficial despite limited systematic studies. Additionally, passionflower, chamomile, hops, skullcap, ginkgo, and gotu cola might be beneficial for symptoms of anxiety and insomnia in patients with bipolar disorder, but further studies are warranted in order to determine their efficacy and safety.

Many of these available 'over-the-counter' (OTC) psychotropic herbal medicines are reasonably safe and present with fewer side effects in comparison to conventional pharmacotherapies such as antidepressants and benzodiazepines. In addition, the mechanisms of action for some of these herbal medicines involve monoaminergic or melatonergic systems, which may have potential synergistic effects on the treatment of bipolar disorder.

Although natural remedies are attractive agents for the treatment of anxiety and insomnia, other pharmacologic agents are definitely better in terms of efficacy. Atypical antipsychotics, anxiolytic anticonvulsants, and cognitive therapy have established efficacy. Under-treatment of anxiety and insomnia worsens the morbidity and mortality of bipolar disorder.
If patients are suffering from clinically significant anxiety and insomnia, aforementioned conventional approaches should be tried before considering herbal medications. Herbal medications need to be considered only in mild cases or after trying these conventional treatments. Both clinicians and patients should be aware of potential risks of under-treatment related to choosing herbal medicines instead of the conventional therapies. When herbal medicines are used with other conventional therapies, they also need to be aware of possible drug-drug interactions.

Despite limited evidence from currently available studies, herbal medicines may have beneficial effects on anxiety and insomnia in patients with bipolar disorder. The herbal medicines discussed in our paper deserve further investigation, and additional studies are needed to prove their efficacy.

The present research investigated the putative CNS effect of an ethanolic extract of roots of Valeriana wallichii. The results showed that EEVW exerts sedative and hypnotic effect on the CNS. Moreover, it was also found that acute oral administration of EEVW at the doses of 1000,2000 , and $3000 \mathrm{mg} / \mathrm{kg}$ did not produce any allergic manifestations or mortality during the observation period of $72 \mathrm{~h}$ after administration. Therefore, it is conceivable that EEVW may not be toxic at our experimental doses up to $3000 \mathrm{mg} / \mathrm{kg}$.

Table-1: Effect of EEVW on Hole cross test

\begin{tabular}{|c|c|c|c|c|c|c|}
\hline \multirow[t]{2}{*}{ Treatment } & \multirow{2}{*}{$\begin{array}{c}\text { Dose } \\
(\mathrm{mg} / \mathrm{kg})\end{array}$} & \multicolumn{5}{|c|}{ Number of holes crossed (\% of inhibition) } \\
\hline & & $\begin{array}{c}\text { Pre- } \\
\text { treatment }\end{array}$ & $30 \mathrm{~min}$ & $60 \mathrm{~min}$ & $90 \mathrm{~min}$ & $120 \mathrm{~min}$ \\
\hline Control & $\begin{array}{c}0.1 \\
\mathrm{~mL} / \mathrm{mouse}\end{array}$ & $19 \pm 1.58$ & $17.60 \pm 0.75$ & $15.6 \pm 0.93$ & $13.4 \pm 0.51$ & $12.4 \pm 0.51$ \\
\hline Diazepam & 1 & $21.2 \pm 1.63$ & $\begin{array}{c}5.2 \pm 1.16^{*} \\
(70.45)\end{array}$ & $\begin{array}{c}3.2 \pm 0.37^{*} \\
(79.49)\end{array}$ & $\begin{array}{c}2.0 \pm 0.45^{*} \\
(85.07)\end{array}$ & $\begin{array}{c}2.2 \pm 0.74^{*} \\
(82.26)\end{array}$ \\
\hline EEVW & 50 & $18.6 \pm 1.69$ & $\begin{array}{c}12.6 \pm 1.54^{*} \\
(28.41)\end{array}$ & $\begin{array}{c}10.2 \pm 1.20^{*} \\
(34.62)\end{array}$ & $\begin{array}{c}7.2 \pm 1.16^{*} \\
(46.27)\end{array}$ & $\begin{array}{c}4.2 \pm 0.97^{*} \\
(66.13)\end{array}$ \\
\hline EEVW & 100 & $20.4 \pm 1.08$ & $\begin{array}{c}8.80 \pm 0.49^{*} \\
(50.00)\end{array}$ & $\begin{array}{c}7.8 \pm 1.02^{*} \\
(50.00)\end{array}$ & $\begin{array}{c}3.6 \pm 0.81^{*} \\
(73.13)\end{array}$ & $\begin{array}{c}3.2 \pm 0.86^{*} \\
(74.19)\end{array}$ \\
\hline EEVW & 200 & $21 \pm 0.84$ & $\begin{array}{c}6.0 \pm 0.84^{*} \\
(65.91)\end{array}$ & $\begin{array}{c}2.0 \pm 0.71^{*} \\
(87.18)\end{array}$ & $\begin{array}{c}1.6 \pm 0.4^{*} \\
(88.06)\end{array}$ & $\begin{array}{c}1.2 \pm 0.37^{*} \\
(90.32)\end{array}$ \\
\hline
\end{tabular}

Values are presented as the Mean $\pm \operatorname{SEM}(n=5) . E E V W=$ ethanolic extract of Valeriana wallichii; ${ }^{*} P<0.05$ compared with the control group (two-way ANOVA followed by Bonferroni test).

We started our investigation for the sedative effects of EEVW by recording spontaneous locomotor activity of mice in Hole cross and open field tests. In these tests, any agents with sedative properties will produce a decrease in the number of movements, interpreted as a decrease in curiosity of the new environment [19, 23]. Our result demonstrated that the oral administration of EEVW in all doses $(50,100$, and $200 \mathrm{mg} / \mathrm{kg}$ ) caused a marked reduction in number of hole crossed (Table 1). The suppressive effect was found at $30 \mathrm{~min}$ and continued up to $120 \mathrm{~min}$ after administration of EEVW. Also, similar types of responses were observed in the open field test. EEVW at all tested doses produced significant $(P<0.05)$ inhibition of locomotion that was maintained from 30 min to $120 \mathrm{~min}$ of observation period (Table 2). This ability of EEVW to suppress the locomotor activity suggests that the extract is endowed with central nervous system depressant activity.

Another important observation was achieved in the Hole board test. This test is well-established as a means to assay potential anxiolytic and sedative effects of any agents by observing the exploratory behaviour in rodents. This experiment is advantageous due to its methodological simplicity and several behavioural 
responses of an animal can be readily observed and quantified when exposed to an unfamiliar environment. It was found that the head-dipping behaviour of the animals is directly related to their emotional state. Based on this observation, it was suggested that the expression of an anxiolytic state in animals might be reflected by an increase in head-dipping behaviour [24], while a decrease in the number of head dips was found to be correlated with the depressant effect $[25,26]$. Our results revealed that the ethanolic extract of Valeriana wallichii caused a dose-dependent reduction in head-dip response in the animals $(23.84,45.55$ and $70.46 \%$ headdip inhibition for 50,100 and $200 \mathrm{mg} / \mathrm{kg}$ doses, respectively) suggesting that the extract possesses sedative activity rather than anxiolytic potentials. The observed effects in the treated groups were significantly different $(P<0.05)$ from that of the control group (Table 3).

Table-2: Effect of EEVW on Open field test

\begin{tabular}{|c|c|c|c|c|c|c|}
\hline \multirow[t]{2}{*}{ Treatment } & \multirow{2}{*}{$\begin{array}{c}\text { Dose } \\
(\mathrm{mg} / \mathrm{kg})\end{array}$} & \multicolumn{5}{|c|}{ Number of holes crossed (\% of inhibition) } \\
\hline & & Pre-treatment & $30 \mathrm{~min}$ & $60 \mathrm{~min}$ & $90 \mathrm{~min}$ & $120 \mathrm{~min}$ \\
\hline Control & $\begin{array}{c}0.1 \\
\mathrm{~mL} / \mathrm{mouse}\end{array}$ & $102.8 \pm 2.99$ & $93.2 \pm 3.31$ & $83 \pm 3.67$ & $67.8 \pm 1.93$ & $56.4 \pm 2.79$ \\
\hline Diazepam & 1 & $97.4 \pm 6.08$ & $\begin{array}{c}47.4 \pm 1.66^{*} \\
(49.14)\end{array}$ & $\begin{array}{c}29.2 \pm 2.46^{*} \\
(64.82)\end{array}$ & $\begin{array}{c}13.6 \pm 2.09^{*} \\
(79.94)\end{array}$ & $\begin{array}{c}8.8 \pm 0.86^{*} \\
(84.40)\end{array}$ \\
\hline EEVW & 50 & $95.2 \pm 5.83$ & $\begin{array}{c}59.4 \pm 1.66^{*} \\
(36.27)\end{array}$ & $\begin{array}{c}43.4 \pm 3.50^{*} \\
(47.71)\end{array}$ & $\begin{array}{c}27.6 \pm 5.85^{*} \\
(59.29)\end{array}$ & $\begin{array}{c}19.6 \pm 2.32^{*} \\
(65.25)\end{array}$ \\
\hline EEVW & 100 & $99.4 \pm 6.40$ & $\begin{array}{c}46.6 \pm 9.32^{*} \\
(50)\end{array}$ & $\begin{array}{c}31.8 \pm 4.87^{*} \\
(61.69)\end{array}$ & $\begin{array}{c}15.8 \pm 2.91^{*} \\
(76.70)\end{array}$ & $\begin{array}{c}9.8 \pm 2.76^{*} \\
(82.62)\end{array}$ \\
\hline EEVW & 200 & $98.4 \pm 5.34$ & $\begin{array}{c}39.6 \pm 1.50^{*} \\
(57.51)\end{array}$ & $\begin{array}{c}20.6 \pm 2.25^{*} \\
(75.18)\end{array}$ & $\begin{array}{c}7.6 \pm 0.93^{*} \\
(88.79)\end{array}$ & $\begin{array}{c}3.20 \pm 0.86^{*} \\
(94.33)\end{array}$ \\
\hline
\end{tabular}

Values are presented as the Mean $\pm \operatorname{SEM}(n=5) . E E V W=$ ethanolic extract of Valeriana wallichii; ${ }^{*} P<0.05$ compared with the control group (two-way ANOVA followed by Bonferroni test).

The Rota rod test is a widely used method to evaluate the motor coordination or muscle relaxant effect in rodents. Our results demonstrated that treatment with EEVW at 50,100 and $200 \mathrm{mg} / \mathrm{kg}$ doses markedly reduced the falling latency of the animals from the rotating rod. The decrement of the latency was calculated as $12.88,43.98$ and $66.05 \%$ of the respective control, for 50,100 , and $200 \mathrm{mg} / \mathrm{kg}$ doses, respectively, where the effect produced by the latter two doses are statistically significant $(P<0.05)$ (Table 4$)$. It is well established that some benzodiazepines like diazepam cause muscle weakness [27], decrease of ambulatory activity, and sedation, thus impairing the performance of rodents in the rota-rod [28,29]. As expected, we also found that diazepam at $1 \mathrm{mg} / \mathrm{kg}$ dose caused muscle relaxation of the animals causing a decrement of the falling time in rota-rod. This same fashion of effect, produced by EEVW and diazepam, influenced us to conceive that EEVW can induce sedative effect by affecting the general activity and motor coordination of the animals.

Table 3: Effect of EEVW on Hole board test

\begin{tabular}{|c|c|c|c|}
\hline \multirow{2}{*}{ Treatment } & Dose (mg/kg) & \multicolumn{2}{|c|}{ Responses } \\
\cline { 3 - 4 } & & Number of head dips & \% Inhibition \\
\hline Control & $0.1 \mathrm{~mL} / \mathrm{mouse}$ & $56.2 \pm 2.27$ & 0 \\
\hline Diazepam & 1 & $13.8 \pm 2.04^{*}$ & 75.44 \\
\hline EEVW & 50 & $42.8 \pm 2.42^{*}$ & 23.84 \\
\hline EEVW & 100 & $30.6 \pm 2.71^{*}$ & 45.55 \\
\hline EEVW & 200 & $16.6 \pm 1.47^{*}$ & 70.46 \\
\hline
\end{tabular}

Values are presented as the Mean \pm SEM $(n=5) . E E V W=$ ethanolic extract of Valeriana wallichii; ${ }^{*} P<0.05$ compared with the control group (one-way ANOVA followed by Dunnett's test).

Table 4: Effect of EEVW on Motor coordination of mice

\begin{tabular}{|c|c|c|c|}
\hline \multirow{2}{*}{ Treatment } & \multirow{2}{*}{ Dose (mg/kg) } & \multicolumn{2}{|c|}{ Responses } \\
\cline { 3 - 4 } & & Number of head dips & \% inhibition \\
\hline Control & $0.1 \mathrm{~mL} / \mathrm{mouse}$ & $119.6 \pm 8.47$ & 0 \\
\hline Diazepam & 1 & $26.6 \pm 2.99^{*}$ & 77.76 \\
\hline EEVW & 50 & $104.2 \pm 4.26^{*}$ & 12.88 \\
\hline EEVW & 100 & $67.0 \pm 3.61^{*}$ & 43.98 \\
\hline EEVW & 200 & $40.6 \pm 4.82^{*}$ & 66.05 \\
\hline
\end{tabular}

Values are presented as the Mean \pm SEM $(n=5) . E E V W=$ ethanolic extract of Valeriana wallichii; * $P<0.05$ compared with the control group (one-way ANOVA followed by Dunnett's test). 
There are several reports which demonstrated that the alkaloids, glycosides, and flavonoids rich plant and plant extracts possess sedative, anxiolytic, and antiepileptic properties mediated through their affinity (in-vitro) with benzodiazepine site of GABAergic complex system or are direct or indirect modulators of this receptor [30-34]. Besides, non-specific CNS depression can also be attributed by tannin [35]. Therefore it appears that the abovementioned phytochemicals present in the EEVW may contribute at least in part to the sedative and hypnotic effects on the CNS.

\section{CONCLUSION}

In conclusion, the present findings in our study indicate that Valeriana wallichii possesses strong sedative and hypnotic activities. The effect is rapid, long-lasting, and statistically significant at all the experimental doses tested. However, further studies are needed to isolate bioactive compound(s) and elucidate the precise molecular mechanisms responsible for the pharmacological activities of the plant.

Valeriana wallichii (Tagara) is used in Indian traditional system of medicine due to various medicinal properties. Recent researchers suggest that it exhibits various properties like anxiolytic activity, anti-stress activity, anti-depressant activity, anti-spasmodic activity, hypotensive effect, sleep inducer activity and anti-hepatotoxic activity. These evidences validate the ancient claim of Ayurveda regarding therapeutic potential of Valerian wallichii. Our study on the ethanolic extract of whole plant Valeriana wallichii on Swiss albino mice revealed that, the whole plant possess better sedative and hypnotic effect. But more studies are required for further validation in replication of results.

The present overview has clearly revealed that, it will be beneficial to establish or to start pharmaceutical industry for the production of herbal drugs of purity, safety and high therapeutic values with more commercial profits. The present study also provides an opportunity to investigate and establish the status of Valeriana wallichii will find their use for the utilization in different ailments. It is anticipated that this work will provide some valuable information for ongoing explorations of this fascinating species and its phytochemicals.

Furthermore, phytochemical investigation of the plant extracts is an important tool for the determination of the phytochemicals, responsible for specific pharmacological activity. An extensive literature survey on the plant Valeriana wallichii revealed its potential utilization as traditional medicine for treating human and veterinary ailments.

\section{DECLARATIONS \\ Acknowledgement}

The authors wish to thank the management of School of Pharmacy, Anurag University, Venkatapur, Ghatkesar, Telangana, India for providing necessary equipment for research, praiseworthy inspiration, constant encouragement, facilities and support.

\section{Author contributions}

All authors contributed to data collection, drafting or revising the article, gave final approval of the version to be published, and agree to be accountable for all aspects of the work.

\section{Funding statement}

This research did not receive any specific grant from funding agencies in the public, commercial, or not-for-profit sectors.

\section{Competing interest statement}

All authors declare that there is no conflict of interests regarding publication of this paper.

\section{Additional information}

No additional information is available for this paper.

\section{REFERENCES}

1. Dhawan K, Dhawan S, Chhabra S. Attenuation of benzodiazepine dependence in mice by a trisubstituted benzoflavone moiety of Passiflora incarnata Linneaus: a non-habit forming anxiolytic. J Pharm Pharm Sci. 2003 May 1;6(2):215-2.

2. De Farias Freire SM, Da Silva Emim JA, Lapa AJ, Souccar C, Torres LM. Analgesic and antiinflammatory properties of Scoparia dulcis L. extracts and glutinol in rodents. Phytotherapy Research. 1993 Nov;7(6):408-14.

3. Zulfiker AH, Rahman MM, Hossain MK, Hamid $\mathrm{K}$, Mazumder ME, Rana MS. In vivo analgesic activity of ethanolic extracts of two medicinal plants-Scoparia dulcis L. and Ficus racemosa Linn. Biol Med. 2010;2(2):42-8.

4. Rampalli SVM, Gudepu R, Rabbani MM and Janapathi YK: Sedative and hypnotic activity of bulbs of Allium cepa Linn. Int J Pharm Sci Res. 2013; 4(12): 4650-55.

5. Bose A, Khuntia A, Gupta JK, Si S. Evaluation of central nervous system depressant activity of Cleome rutidosperma. Alternative Medicine Studies. 2012; 2(1):8.

6. Fernandez S, Wasowski C, Paladini AC, Marder M. Sedative and sleep-enhancing properties of linarin, a flavonoid-isolated from Valeriana officinalis. Pharmacology Biochemistry and Behavior. 2004; 77(2):399-404.

7. Khan IN, Sarker MM, Ajrin M. Sedative and anxiolytic effects of ethanolic extract of Calotropis gigantea (Asclepiadaceae) leaves. Asian Pacific 
journal of tropical biomedicine. 2014 May $1 ; 4: \mathrm{S} 400-4$

8. Aguirre-Hernández E, González-Trujano ME, Terrazas T, Santoyo JH, Guevara-Fefer P. Anxiolytic and sedative-like effects of flavonoids from Tilia americana var. mexicana: GABAergic and serotonergic participation. Salud Mental. 2016 Mar 15;39(1):37-46.

9. Jiang JG, Huang XJ, Chen J, Lin QS. Comparison of the sedative and hypnotic effects of flavonoids, saponins, and polysaccharides extracted from Semen Ziziphus jujube. Natural Product Research. 2007 Apr 1;21(4):310-20.

10. Pandey A, Tripathi S. Concept of standardization, extraction and pre phytochemical screening strategies for herbal drug. Journal of Pharmacognosy and Phytochemistry. 2014 Jan $1 ; 2(5)$.

11. Herrera-Ruiz M, Gutiérrez C, Jiménez-Ferrer JE, Tortoriello J, Mirón G, León I. Central nervous system depressant activity of an ethyl acetate extract from Ipomoea stans roots. Journal of ethnopharmacology. 2007 Jun 13;112(2):243-7.

12. Huang F, Xiong Y, Xu L, Ma S, Dou C. Sedative and hypnotic activities of the ethanol fraction from Fructus Schisandrae in mice and rats. Journal of Ethnopharmacology. 2007 Apr 4;110(3):471-5.

13. Rakhshandah $\mathrm{H}$, Hosseini $M$ and Dolati $K$. Hypnotic effect of Rosa damascena in Mice. Iran. J. Pharm. Res. 2004; 3: 181 -185.

14. Venâncio ET, Rocha NF, Rios ER, Feitosa ML, Linhares MI, Melo FH, Matias MS, Fonseca FN, Sousa FC, Leal LK, Fonteles MM. Anxiolytic- like effects of standardized extract of Justicia pectoralis (SEJP) in mice: Involvement of GABA/benzodiazepine in receptor. Phytotherapy Research. 2011 Mar;25(3):444-50.

15. Sundaresan Nandhini, Kasthuri Bai Narayanan, Kaliappan Ilango. Valeriana Officinalis: A Review of Its Traditional Uses, Phytochemistry and Pharmacology. Asian J Pharm Clin Res. 11,(1) 2018, 36-41.

16. Benke D, Barberis A, Kopp S, Altmann KH, Schubiger M, Vogt KE, Rudolph U, Möhler H. GABAA receptors as in vivo substrate for the anxiolytic action of valerenic acid, a major constituent of valerian root extracts. Neuropharmacology. 2009 Jan 1;56(1):174-81.

17. Islam NU, Khan I, Rauf A, Muhammad N, Shahid M, Shah MR. Antinociceptive, muscle relaxant and sedative activities of gold nanoparticles generated by methanolic extract of Euphorbia milii. BMC Complement Altern Med. 2015;15:160.

18. Yemitan OK, Salahdeen HM. Neurosedative and muscle relaxant activities of aqueous extract of Bryophyllum pinnatum. Fitoterapia. 2005 Mar 1;76(2):187-93.

19. Takagi K, Watanabe M, SAITO H. Studies of the spontaneous movement of animals by the hole cross test; effect of 2-dimethyl-aminoethanol and its acyl esters on the central nervous system. The Japanese Journal of Pharmacology. 1971;21(6):797-810.

20. Gupta BD, Dandiya PC, Gupta ML. A psychopharmacological analysis of behaviour in rats. Japanese journal of pharmacology. 1971 Jan 1;21(3):293-8.

21. Öztürk Y, Aydin S, Beis R, Başer KH, Berberoĝlu H. Effects of Hypericum perforatum L. and Hypericum calycinum L. extracts on the central nervous system in mice. Phytomedicine. 1996 Sep $1 ; 3(2): 139-46$.

22. Fujimori H, Cobb DP. Central nervous system depressant activity of ma1337, 3-[3-(4-Mchlorophenyl-1-piperazyl) PROPYL]-2, $4(1 \mathrm{H}, 3 \mathrm{H})$ quinazolinedione hydrochloride. Journal of Pharmacology and Experimental Therapeutics. 1965 May 1;148(2):151-7.

23. Prut L, Belzung C. The open field as a paradigm to measure the effects of drugs on anxiety-like behaviors: a review. European journal of pharmacology. 2003 Feb 28;463(1-3):3-3.

24. Takeda H, Tsuji M, Matsumiya T. Changes in head-dipping behavior in the hole-board test reflect the anxiogenic and/or anxiolytic state in mice. European journal of pharmacology. 1998 May 29;350(1):21-9.

25. File SE, Pellow S. Intrinsic actions of the benzodiazepine receptor antagonist Ro 15-1788. Psychopharmacology. 1986 Jan;88(1):1-1.

26. Viola H, Wasowski C, De Stein ML, Wolfman C, Silveira R, Dajas F, Medina JH, Paladini AC. Apigenin, a component of Matricaria recutita flowers, is a central benzodiazepine receptorsligand with anxiolytic effects. Planta medica. 1995 Jun;61(03):213-6.

27. López-Rubalcava C, Hen R, Cruz SL. Anxiolyticlike actions of toluene in the burying behavior and plus-maze tests: differences in sensitivity between 5-HT1B knockout and wild-type mice. Behavioural brain research. 2000 Oct 1;115(1):85-94.

28. Farkas S, Berzsenyi P, Kárpáti E, Kocsis $P$, Tarnawa I. Simple pharmacological test battery to assess efficacy and side effect profile of centrally acting muscle relaxant drugs. Journal of Pharmacological and Toxicological methods. 2005 Sep 1;52(2):264-73.

29. R. Estrada-Reyes, M. Mart'inez-V'azquez, A. Gallegos-Sol'1s, G. Heinze, and J.Moreno, "Depressant effects of Clinopodiummexicanum Benth. Govaerts (Lamiaceae) on the central nervous system," Journal of Ethnopharmacology, 130(1): 1-8, 2010.

30. Fernández S, Wasowski C, Paladini AC, Marder M. Sedative and sleep-enhancing properties of linarin, a flavonoid-isolated from Valeriana officinalis. Pharmacology Biochemistry and Behavior. 2004 Feb 1;77(2):399-404

31. Kahnberg P, Lager E, Rosenberg C, Schougaard J, Camet L, Sterner O, Nielsen EØ, Nielsen M, 
Liljefors T. Refinement and evaluation of a pharmacophore model for flavone derivatives binding to the benzodiazepine site of the GABAA receptor. Journal of Medicinal chemistry. 2002 Sep 12;45(19):4188-201.

32. Trofimiuk E, Walesiuk A, Braszko JJ. St John's wort (Hypericum perforatum) diminishes cognitive impairment caused by the chronic restraint stress in rats. Pharmacological research. 2005 Mar 1;51(3):239-46.

33. Awad R, Ahmed F, Bourbonnais-Spear N, Mullally M, Ta CA, Tang A, Merali Z, Maquin P, Caal F, Cal V, Poveda L. Ethnopharmacology of
Q'eqchi'Maya antiepileptic and anxiolytic plants: effects on the GABAergic system. Journal of Ethnopharmacology. 2009 Sep 7;125(2):257-64.

34. Estrada-Reyes R, López-Rubalcava C, Rocha L, Heinze G, González Esquinca AR, MartínezVázquez M. Anxiolytic-like and sedative actions of Rollinia mucosa: possible involvement of the GABA/benzodiazepine receptor complex. Pharmaceutical Biology. 2010 Jan 1;48(1):70-5.

35. Takahashi RN, De Lima TC, Morato GS. Pharmacological actions of tannic acid; II. Evaluation of CNS activity in animals. Pharm Bull. 1986;31:2150. 